\title{
1971: una mirada desde el retrovisor a los 50 años del movimiento estudiantil en Cartagena, Colombia
}

\section{1: a look from the rearview mirror to the 50 years of the student movement in Cartagena de Indias}

1971: um olhar do retrovisor aos 50 anos do movimento estudantil em
Cartagena de Indias

Diego Alejandro Gutiérrez Velásquez ${ }^{1}$

Universidad Autónoma Metropolitana-México

\begin{abstract}
RESUMEN
El presente escrito tiene como objetivo principal presentar al lector una visión general de los acontecimientos que tuvo lugar en la universidad de Cartagena para 1971, bajo el marco del movimiento estudiantil denominado el "Programa mínimo de los estudiantes colombianos", considerado el mas importante del siglo XX en Colombia, y del cual se conmemoran los 50 años de este suceso. La intención es aportar desde los pormenores, particulares y circunstancias del movimiento estudiantil de la ciudad, al fortalecimiento de la historiografía de este tema en el país, presentando nuevas aristas, enfoques y propuestas relacionada con aspectos como el diario vivir del movimiento, la distinción de personajes representativas para los jóvenes y una propuesta de proceso de apropiación de una figura como el Che Guevara de gran influencia en el movimiento estudiantil.
\end{abstract}

Palabras clave: Movimiento estudiantil; Universidad de Cartagena; protesta social; siglo XX; izquierda revolucionaria.

\begin{abstract}
The main objective of this paper is to present to the reader an overview of the events that took place at the University of Cartagena in 1971, under the framework of the student movement called the "Minimum Program of Colombian students", considered the most important of the 20th century in Colombia, and of which the 50th anniversary of this event is being commemorated. The aim is to contribute from the details, particularities and circumstances of the student movement in the city, to the strengthening of the historiography of this topic in the country, presenting new aspects, approaches and proposals related to aspects such as the daily life of the movement, the distinction of representative characters for young people and a proposed process of appropriation of a figure like Che Guevara of great influence on the student movement.
\end{abstract}

Keywords: Student movement; University of Cartagena; social protest; 20th century; revolutionary political left.

\footnotetext{
${ }^{1}$ Maestría en Historia y Etnohistoria, Escuela de Antropología e Historia ENAH-México. Doctorante en HumanidadesLínea Historia, Universidad Autónoma Metropolitana-México.
}

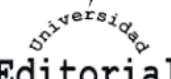
Universitaria \%م. 


\section{RESUMEM}

o objetivo principal deste escrito é apresentar ao leitor um panorama dos acontecimentos ocorridos na Universidade de Cartagena em 1971, no marco do movimento estudantil denominado "Programa Mínimo para Estudantes Colombianos", considerado o mais importante do século XX na Colômbia, e dos quais se comemoram os 50 anos deste evento. A intenção é contribuir desde os detalhes, particularidades e circunstâncias do movimento estudantil da cidade, para o fortalecimento da historiografia dessa temática no país, apresentando novos contornos, abordagens e propostas relacionadas com aspectos como a vida diária do movimento, a distinção de personagens representativos para os jovens, e uma proposta de processo de apropriação de uma figura como Che Guevara com grande influência no movimento estudantil.

Palavras-chave: Movimento estudantil; Universidade de cartagena; protesto social; Século XX; esquerda revolucionária.

\section{Introducción}

A 50 años de los acontecimientos del Movimiento estudiantil denominado programa mínimo de los estudiantes colombianos, presentamos el siguiente escrito como un esfuerzo de cara a los aportes que buscan la consolidación de los estudiantes y jóvenes como sujetos importantes de la historiografía colombiana. En este sentido, nos hemos centrado en el caso de la ciudad de Cartagena como escenario de análisis y la Universidad de Cartagena como epicentro del proceso histórico que contribuyo desde sus manifestaciones, a la estructuración del que se ha considerado por diversos estudiosos del tema ${ }^{2}$, como el movimiento estudiantil más importante del siglo XX en el país.

De esta manera la intención de este artículo es recabar en el movimiento estudiantil de 1971 en la Universidad de Cartagena, para así distinguir sus particularidades, pormenores y características, haciendo evidente el proceso vivido por esta institución y sus estudiantes en este acontecimiento de carácter nacional, presentando una visión que complemente y aporte a la historiografía del tema, aun mas en estos tiempos de aires conmemorativos como son los 50 años de aquel acontecimiento. Para esto, tomamos como punta de lanza de nuestra indagación los testimonios de testigos que vivieron dicho suceso, todo ello para que desde su humanidad presten su mirada a este estudio y podamos analizar desde sus recuerdos como se estableció ese universo de manifestaciones, protestas, arengas, marchas, pinturas, panfletos y más, al cual denominamos movimiento estudiantil.

Pero ¿Qué es el programa mínimo de los estudiantes colombianos? Podemos definirla como un conjunto de manifestaciones detonadas para el mes de febrero de 1971, en las que diferentes universidades del país se agruparon en un bloque común para revelarse en contra de lo que ellos denominaban

\footnotetext{
${ }^{2}$ En este sentido uno de los mayores exponentes del tema es el historiador Álvaro Acevedo Tarazona en textos como: Modernización, conflicto y violencia en la universidad en Colombia: AUDESA, 1953-1984, Bucaramanga, UIS, 2004.
} 
atropellos en contra del sector estudiantil, es así como tenemos la muerte de 15 estudiantes en la ciudad de Cali para mediados del mes de febrero, las manifestaciones en la Universidad Javeriana que dejaron un saldo de estudiantes lesionados $\mathrm{y}$, los más importante, los intentos de reforma educativa que el gobierno conservador de Misael pastrana borrero y su ministro de educación un joven llamado Luis Carlos Galán, intentaban impulsar, que desde el punto de vista de los estudiantes procuraba un detrimento de la educación superior país, siendo una extensión del plan ATCON $^{3}$ de educación formulada desde los Estados Unidos en el marco de la Alianza para el progreso 4 ; por todo esto esa reforma fue tildada de intervencionismo estadounidense.

Los estudiantes se organizaron en diferentes asambleas que se repartieron por diversas sedes alrededor del país siendo 6 en total ${ }^{5}$, una de estas las numero III llevada a cabo en Palmira para el 25 del mes de abril vio el nacimiento del documento que dio nombre al movimiento, el "Programa mínimo de estudiantes colombianos", escrito parte pliego petitorio, contrapropuesta a la reforma educativa y respuesta a los acontecimientos de abuso policial que se habían presentado hasta el momento. Es así como 1971 encaja como una coyuntura de convulsión marcada por características políticas como un gobierno conservador bajo el marco del pacto del frente nacional, que conllevo a la imposibilidad de nuevas opciones políticas que aumentaron el descontento de sectores como el estudiantil y obrero que veían mermadas las posibilidades de nuevos aires gubernamentales.

En un plano más amplio, el mundo fluctuaba entre la disputa de los dos órdenes presentes en la guerra fría, y más cercano nuestro escrito, las manifestaciones de estudiantes resonaron a lo largo del planeta Mayo del 68, la matanza de Tlatelolco, la primavera de Praga, manifestaciones en estudiantiles en países como Argentina, Brasil y Uruguay, los Hippies, el movimiento por los derechos civiles; y otros acontecimientos como la influencia de la revolución cubana en Latinoamérica y la muerte de Che convertido en ídolo para muchos jóvenes; marcaron este periplo de finales de la década de 1960 e inicios de 1970 en donde podemos ubicar a nuestro objeto

\footnotetext{
${ }^{3}$ El plan ATCON, es un conjunto de propuestas de reforma educativa impulsada por los EE. UU y su nombre deriva de Rudolph Atcon, asesor del gobierno norteamericano para América Latina en la década de 1960, en palabras del estudioso Álvaro Acevedo Tarazona, "Atcon proponía una institución totalmente autónoma. Su noción de autonomía universitaria refería una emancipación total de cualquier forma de dominio directo o indirecto que atentara contra los objetivos científicos y democráticos propios de la universidad. La autonomía respondía, entonces, a principios como el de "un máximo de rendimiento con la menor inversión de las disponibilidades financieras dentro de su limitadísimo presupuesto anual", al igual que el procurarse nuevas fuentes de ingreso para garantizar la expansión" Véase; Tarazona, Álvaro Acevedo, "Educación, reformas y movimientos universitarios en Colombia: apuestas y frustraciones por un proyecto modernizador en el siglo XX". Revista de Estudios Sociales 53, (2015): 102-111. http://dx.doi.org/10.7440/res53.2015.08 20-12-2017

${ }^{4} \mathrm{La}$ alianza para el progreso se constituye en un conjunto de planes de ayuda para Latinoamérica, estipuladas por J.F Kennedy durante su mandato, que buscaban mantener las alianzas de los vecinos del sur del continente ante la presencia de la URSS durante la guerra fría. Para mayor información véase, Lázaro Díaz Fariñas, "A cincuenta años de la alianza para el Progreso: el debate por el socialismo". Economía y Desarrollo, 149, 1, (2013): 139-157.

${ }^{5}$ Algunas sedes de los encuentros fueron Cali 22 y 23 de febrero, Bogotá 13 y 14 de marzo, Palmira 3 y 4 de abril, Cali 24 de abril, inicialmente barranquilla posteriormente Bogotá 18-24 de mayo, Medellín 3 de junio; véase: "Programa mínimo de estudiantes colombianos" http://es.scribd.com/doc/52353497/Programa-Minimo-de-los-Estudiantes-Colombianos; Isabel Hernández, "Programa mínimo de los estudiantes colombianos. Movimiento estudiantil universitario de 1971 por la universidad. Todo un país”. Revista Historia de la Educación Colombiana, (2007): 29-57.
} 
de estudio. Todo este recorrido presentado hasta aquí tiene la intención de ubicar al lector en nuestro proceso de investigación, proporcionando una mirada más certera del escenario internacional y nacional que pudo tener un impacto los sujetos de estudio del presente escrito.

Pasando a otro componte de vital importancia para el presente escrito, desde el punto de vista metodológico definimos la investigación como un estudio desde los recuerdos de los participantes, a los que hemos intentado acercarnos desde la historia oral, centrándonos en entrevistas realizadas los exestudiantes que vivieron los hechos en 1971 en la Universidad e Cartagena. De esta manera partimos del manifiesto que nos señala que los recuerdos "no son estáticos sino que se van adaptando a las diferentes condiciones sociales y políticas que se viven para legitimar la presencia de los grupos sociales dentro y fuera de la comunidad", 6 lo que nos permite hacer una revisión de los acontecimientos vividos, las personas y afiliaciones a los que se vieron abocados estos jóvenes, proporcionando las herramientas para reconstruir el escenario de la protesta.

Acompañado de lo anterior, no asumimos la historia oral como un ejercicio que busca construir sus propias fuentes, más allá de esto la entendemos como una historia viva, cambiante, transformadora y transgresora ${ }^{7}$ en la que se inserta tanto el entrevistado como el entrevistador como partes esenciales del proceso de indagación, con respecto a este enfoque historiadores como Mario Camarena y Rocío Guzmán expresan lo siguiente:

El centro de la reflexión del historiador o la oral es la vivencia de las personas acerca de los hechos y los recuerdos que de ellos tienen. Si bien los hechos son importantes, lo es más el recuerdo y los referentes culturales que esté denota.

la enseñanza de la historia oral se centra en tres puntos metodológicos interrelacionados: la realización de la entrevista, el análisis de la misma y la forma de exponer los resultados de investigación a partir de esa fuente. Estos niveles se hallan unidos y sólo se les separa con fines explicativos. En este proceso el papel del historiador/entrevistador resulta central, este crea el documento oral es quien lo interpreta y expone sus resultados ${ }^{8}$.

En conjunto con la fuente oral, las fuentes de prensa tanto para la ciudad de Cartagena ayudaron al proceso de contextualización y entendimiento de procesos ocurridos. Si bien, esta fuente no es eje central para el proceso de indagación de nuestra investigación, sirve de ayuda al momento de comprender los hechos establecidos a lo largo de nuestro periodo de estudio.

\footnotetext{
${ }^{6}$ Mario Camarena Ocampo (coord.), La construcción de la memoria colectiva. México: Instituto Nacional de Antropología e Historia/Escuela Nacional de Antropología e Historia/Concejo Nacional para la Cultura y las Artes, 2010 , p. 8.

${ }^{7}$ Graciela de Garay Arellano, "De la palabra a la escucha. Una reflexión sobre la legitimidad del testimonio oral", en Graciela de Garay Arellano y Jorge Eduardo Acevedo Lozano (coord.), Entrevistas ¿para qué? Múltiples escuchas desde diversos cuadrantes. México: Instituto de Investigaciones Dr. José María Luis Mora, 2017, pp. 91-125.

${ }^{8}$ Mario Camarena Ocampo y Rocío Martínez Guzmán, "Memoria de un proyecto comunitario: tejiendo testimonios". Diario de Campo, 9. México: INAH, 2015, p. 60.
} 
De manera concreta se han adoptado dos periódicos el Diario de la Costa y El Universal. Cada de uno de estos periódicos, opuestos con sus perspectivas particulares en cuanto a los acontecimientos del movimiento estudiantil; tenemos entonces El Universal de Cartagena, más benignos en los informes referentes a los estudiantes, mientras que El Diario de la Costa de Cartagena, más férreos en sus críticas. De manera general estos periódicos construyeron un discurso de contraposición a los estudiantes del movimiento estudiantil, siendo para nuestro estudio la voz de los estamentos estatales, que tomaban a los periódicos de la época como herramientas para la difusión de sus ideas y apreciaciones con respecto a los acontecimientos sociales y políticos.

En cuanto a la parte teórica nos movemos bajo la teoría de nuevos movimientos sociales, "el paradigma de los nuevos movimientos sociales se trata de las contradicciones ente el individuo y el Estado: nuevos valores que cuestiona el estado de las cosas, a partir de intereses sociales universales ${ }^{9}$. Bajo este panorama entendemos por movimiento estudiantil: a los grupos pertenecientes a sectores modernos de la sociedad y la economía, relacionados con la ciencia y la tecnología y, en general con la producción de conocimientos modernos. Caracterizados por tener una conciencia de grupo e ideas definida, demandas específicas, activistas y un desempeño que trascurre de la mediación o la concertación hasta la vía de los hechos ${ }^{10}$.

Ahora bien, desde la parte estructural, en la próximas paginas tendremos un acercamiento al escenario de Cartagena y la su universidad dentro del año de 1971, percibiendo sus particularidades y distinciones. Seguidamente expondremos el universo del movimiento estudiantil dentro de la universidad de Cartagena. seguidamente analizaremos la consolidación de figuras públicas de gran valor, que siendo apropiadas por los estudiantes se convirtieron es sus referentes de lucha y definen en gran medida el carácter político, social y cultural de los estudiantes. Para finalizar, se expondrá un ejercicio en el cual se explica el proceso de apropiación de una figura que como Ernesto Guevara tuvo gran influencia en el movimiento estudiantil de la ciudad.

\section{El escenario de la Universidad de Cartagena}

En la ciudad al igual que en el resto país se incrementaron para 1971 las opiniones y manifestaciones de diferentes sectores de la sociedad, centrales obreras, profesores, estudiantes se sentían inconformes con la política gubernamental y la condición social que afrontaban. Los estudiantes sobresalieron del resto por su mayor dinamismo, levantando sus voces para reclamar en contra de lo que catalogaban como atropellos como las reformas educativas y agraria, es así como paros, rechiflas, pronunciamientos en

\footnotetext{
9 José María Aranda, "El movimiento estudiantil una teoría de los movimientos sociales". Convergencia, 21. Centro de Investigación en Ciencias Sociales y Humanidades UAEM, p. 228. http://convergencia.uaemex.mx rev21/pdf/aranda.PDF 17/08/2012

${ }^{10}$ J. M. Aranda, "El movimiento estudiantil", pp. 244-247
} 
medios de comunicación como los periódicos, y en general un aura de protesta, caracterizaron sus acciones.

Para poder comprender toda esta situación se hace indispensable el reconocimiento de algunos elementos. El primero de ellos es la condición política de la ciudad, que para ese momento como en todo el territorio, estaba siendo gobernada por el partido conservador de turno dentro del pacto bipartidista conocido como Frente Nacional; a la cabeza de la alcaldía se encontraba Enrique Zurek, encargado junto al gobernador Álvaro de Zubaría de manejar la política de la ciudad y el departamento de Bolívar. Bajo sus mandatos se gestaron diversas protestas llevadas a cabo en primera medida por el sindicato del magisterio tanto en Bolívar como en Cartagena, quienes demandaban mejores condiciones laborales, y en segunda medida y aún más sobresaliente por grupos de estudiantes, que inconformes por la manera en que se estaban ejecutando las políticas educativas, se lanzaban a las calles y tomaban las instituciones como medio para mostrar su desacuerdo.

La Universidad de Cartagena de gran tradición en la zona norte del país, en la región denominada como caribe ${ }^{11}$, para finales de la década de 1960 prestaba servicio educativo principalmente a la población de sectores acomodados de la ciudad, esto sin olvidar algunos estudiantes de escasos recursos que debían trabajar para mantener al día sus colegiaturas y sostenerse como estudiantes. Con esta población diversa se convirtió en uno de los epicentros de las manifestaciones, aumentando entre 1968 y 1971 las acciones contestatarias radicalizándose las protestas y descontentos ${ }^{12}$, motivados por los posibles malos manejos de la administración y la discordia con la política gubernamental.

Así se evidencia en algunos acontecimientos que revelan la situación real que afrontaba el alma mater, en donde a principios de 1971 se presentaron manifestaciones que tenían como objetivo denunciar lo que para muchos alumnos eran casos de corrupción, tal como se muestra en este fragmento del periódico El Universal:

Las directivas de la Universidad de Cartagena se enfrentan, apenas iniciado el año a un movimiento estudiantil de protesta por algunas irregularidades descubiertas en el comité de admisión. La primera reacción de los universitarios fue ordenar un paro de 48 horas que ya se cumplió. Ante este hecho el concejo directivo de la universidad llamó a los inconformes y todo parece indicar que no habrá necesidad de nuevas huelgas y que se restablecerá pronto la normalidad en la Universidad de Cartagena ${ }^{13}$.

\footnotetext{
${ }^{11}$ Ya para 1827 el general Francisco de Paula Santander y el libertador Simón Bolívar, crearon esta institución con la intención de formar ciudadanos capacitados que sirvan a la república naciente hace menos de 10 años.

${ }^{12}$ Amalfi Padilla Castilla, "Organizaciones estudiantiles en la Universidad de Cartagena: reconocimiento partidismo y relaciones de poder (1948-1980)". Revista Historia de la Educación Colombiana, 12, (2009): 146. www.udenar.edu.co. $25 / 02 / 2011$

${ }^{13}$ Frank Camus, "Paradojas”, en Archivo El Universal (en adelante AEU), El Universal, Cartagena, 17 febrero de 1971.
} 
Paralelamente, los educadores realizaban paros de actividades académicas y manifestaban su apoyo a los estudiantes al igual que otros sectores como el obrero $^{14}$, hechos que muchas veces motivaron despidos, dejando a la vista las medidas adoptadas por las directivas, que eran de algún modo una extensión del gobierno estatal ${ }^{15}$ quien escogía sus miembros más importantes, como el rector, por ejemplo, ello demuestra los diferentes niveles y personajes inmersos en los eventos. De tal manera las dinámicas impuestas en la institución fueron en parte, resultado de la incursión de las políticas e intereses gubernamentales en los asuntos inherentes a los establecimientos de educación superior, y el impacto e importancia ganada por las movilizaciones estudiantiles y académicos en la ciudad y el país ${ }^{16}$.

Con todo esto será hasta el mes de abril que en la ciudad de Cartagena se consolido el movimiento estudiantil, que empezó a realizar asambleas y paros relámpago de 24 y 48 horas, así como mítines, marchas y manifestaciones que procuraban mostrar la ciudad de Cartagena los inconvenientes y dificultades que tenía el Alma Mater, relacionados con las dificultades económicas, una posible reforma educativa nacional y el intervencionismo estadounidense en la educación. Esto siguió hasta establecerse para el mes de julio al reingreso de los estudiantes luego de vacaciones, cuando aumentaron los enfrenamientos entre los estudiantes y las autoridades de la institución, derivando un mes después en la presentación de la renuncia del rector Juan C. Arango' que solo se haría efectivo hasta el mes de septiembre, su renuncia fue motivada por los estudiantes quienes se habían salido de su control. Es aquí donde se estipula un nuevo pasaje dentro de la movilización estudiantil, en la cual las instalaciones son cada vez más controladas por los estudiantes, que venidos a huelga establecieron de la universidad su bastión, centro de acopio y logística para movilización estudiantil.

Esto no solo ocurrió en Cartagena, sino que tenía diferentes epicentros a lo largo del país, en reuniones donde se discutía el Programa mínimo estudiantes colombianos, una contrapropuesta de las reformas educativas que se querían realizar en el país, que estaba estrechamente vinculadas al plan ATCON y la alianza para el progreso, hecho que aumento el sentimiento antimperialista y antiyankee en los estudiantes. Este último punto para la ciudad de Cartagena toma una vital relevancia, puesto que ya desde finales de 1970, se encontraba atracado en el puerto el barco Hope, un navío de ayuda humanitaria y de educación en medicina de origen estadounidense, que para muchos estudiantes era una forma de intervencionismo estadounidense en la educación y la política de educación de la ciudad, este sentimiento fue expresado en especial por los estudiantes de medicina, quién en diferentes manifestaciones mostraron su descontento con este buque, al punto de precipitar su salida de la ciudad para el mes de septiembre ${ }^{17}$, cuándo fueron

\footnotetext{
14 "Manifestaciones de estudiantes y obreros ayer", AEU, El Universal, Cartagena, mayo 28 de1971.

15 A. Padilla, "Organizaciones estudiantiles", pp. 138-159.

${ }^{16}$ A. Padilla, "Organizaciones estudiantiles", pp. 144-146

17 Guillermo Valderrama, "Pueblo brinda apoyo total al barco HOPE", en Biblioteca Bartolomé Calvo (en adelante BBC), Diario de la Costa, septiembre 17 de 1971.
} 
tomada las instalaciones de esta embarcación por parte de los estudiantes de esta facultad, y otras facultades como economía, derecho y enfermería.

Con todo esto, fue hasta el mes de julio cuándo al regresar de vacaciones los estudiantes van a empapelar las paredes de la universidad con la esfinge del Che Guevara y figuras como Jósef Stalin, Mao Zedong, Fidel Castro, Hồ Chí Minh, Lenin, con decenas de pendones de gran magnitud y la puesta en marcha de la imagen de estos personajes por diversos corredores al interior del claustro de San Agustín, que evidencia la adopción de figuras representativas adoptadas por el movimiento estudiantil.

Todo este escenario se hace evidente con las transformaciones que sufrió el ente administrativo durante el año de 1971. El caso más representativo fue efectuado para el mes de octubre cuando por mandato del gobernador Álvaro de Zubaría fuera remplazado en el cargo de rector Juan Carlos Arango por Manuel Navarro Patrón, un Conservador plenamente convencional y como muchos entrevistados lo han catalogado "de mano fuerte" 18 . Este apelativo es comprensible si se toman en cuenta sus decisiones y los mecanismos utilizados para replegar las críticas y manifestaciones en contra de su persona y el Gobierno; en donde sus herramientas más comunes incluían entradas militares en la universidad, acordonamiento policial y militar de las calles aledañas a la institución, expulsiones y los despidos masivos de profesores y otros empleados ${ }^{19}$; tal como se muestra en diferentes noticias como la siguiente.

Vigilancia policiva

Agentes de la policía nacional con equipos anti-motines y gases lacrimógenos han permanecido en la plaza del estudiante, a pocos pasos de la universidad atentos a cualquier eventualidad.

Como se recordará el rector dijo perentoriamente en su discurso de posesión que solicitaría la presencia de la fuerza pública en el recinto del alma mater cuando considere que las circunstancias lo exigen.

En medios estudiantiles se dijo que los 26 universitarios detenidos el viernes anterior, durante la posesión del nuevo rector han sido puestos en libertad, mediante el pago de multas de 300 y 500 pesos $^{20}$.

Cabe destacar que, junto al arribo del entonces nuevo rector, se presentaron otros acontecimientos y circunstancias que delimitaron las diferentes fases por la que transcurrieron los hechos de aquel año. La primera etapa se abre con las huelgas y paros de actividades académicas en los primeros meses de 1971, llevados a cabo por estudiantes del el Liceo de Bolívar y la Universidad de Cartagena, motivados por situaciones como corrupción institucional y aún

\footnotetext{
18 Jorge Valdelamar, Cartagena, 11 de Julio 2012.

${ }^{19}$ Se habla de un aproximado de 150 expulsiones y despidos entre estudiantes y profesores, este dato puede ser revisado en el siguiente documento, Archivo Universidad de Cartagena (Cartagena-Colombia), Sección Resoluciones de rectoría, Volumen Septiembre-Diciembre. 1971, números: 524 19-10-1971, 525 20-10-1971, 536 22-10-1971, 539 25 -10-1971, 543 26-10-1971.

20 "Disminuye asistencia en universidad local", en AEU, El Universal, Cartagena, octubre 20 de 1971.
} 
más importante lo que consideraron intervencionismo extranjero, así lo señala en el diario El Universal. "Los estudiantes denuncian que la universidad atraviesa por una crítica situación académica, especialmente en la facultad de medicina en la cual algunos cursos no han iniciado labores como protesta por un nuevo plan académico calificado de extranjerizante pues fue elaborado en Estados Unidos"21. Estas concepciones están estrechamente ligadas con las que, a nivel nacional impulsaron por parte del estudiantado el programa mínimo de los estudiantes colombianos.

La segunda etapa inicia con la llegada del barco Hope, situación que causó malestar en un amplio sector del alumnado, desajustado la calma parcial que se había sostenido durante algunos pasajes del año. De manera concreta, el caso del barco Hope no es más que las manifestaciones surgidas por una presunta intervención en la educación superior de la ciudad, de un navío de la marina norteamericana encargado de ofrecer ayuda médica humanitaria a diferentes países de escasos recursos. El hecho que esa embarcación atracara en Cartagena y ofreciera cursos médicos a la población y en especial a los estudiantes del área de la salud de la universidad, repercutió de manera considerable en las concepciones y los valores construidos alrededor de una educación autónoma y sin intervencionismo extranjero, en especial del estadounidense, que para ese tiempo era considerado como el imperialismo yanqui. De esta manera los medios presentaron este caso.

Pasadas las dos de la tarde del día anterior, las oficinas del Programa Hope desaparecieron del hospital universitario, en donde funcionaban desde la ida del Barco-Hospital. Los motivos: un ultimátum lanzado por un "grupito de estudiantes" que con pancartas y palabras de grueso calibre, obligaron a los médicos de ese benemérito programa, salir del sitio, en donde tanto bien han hecho a las personas de escasos recursos económicos.

Los estudiantes "el grupito" que está abanderado con consignas obsoletas como "fuera los lacayos del imperialismo norteamericano de la Universidad", se salieron con la suya, ante la mirada atónita de los estudiantes, amantes del orden y el bien pero que desgraciadamente, en actos como el anterior brillan por su ausencia ${ }^{22}$.

El ver vulnerada la autonomía educativa, acompañada de la posterior oposición a la dirección universitaria a la cabeza del rector Manuel Navarro Patrón, fueron hechos que recrudecieron la situación en la universidad, a partir del ascenso de este personaje, se dio inicio a la tercera etapa que demarcó los sucesos de aquel periodo. Así es presentado este personaje por algunos entrevistados “Aquí nombraron a Manuel Navarro Patrón, un hombre de extrema derecha y violento que fue el que militarizó la universidad, el que puso controles en la entrada, nos botó como a trescientos estudiantes, a

\footnotetext{
21 "Paro en la universidad", en AEU, El Universal, Cartagena, febrero 26 de 1971.

22 "Desalojado programa "Hope" del Santa Clara", en Biblioteca Nacional de Colombia (en adelante BNC), Diario de la Costa, Cartagena, septiembre 10 de 1971.
} 
cuarenta profesores, una represión violenta"23. Se estableció entonces una representación relacionada con el temor y motivada por el impacto de la entrada de un personaje, que como Navarro Patrón fue considerado un perjuicio para la universidad y sus alumnos.

Junto al temor, las representaciones construidas en cuanto a los mecanismos de control impuestos por el Estado y las directivas de la universidad, están repletas de alusiones a la opresión, además de la censura de la que fueron los directamente implicados. Uno de los componentes que mejor ejemplifica la condición de 1971 son las entradas militares y la militarización de las universidades, de ellas se constituyó todo un imaginario, resultado de la creación de un contexto nuevo en la que las instituciones no solo albergaban estudiantes, sino también a la fuerza pública. Una descripción sobresaliente de todo ello la realiza el que fuera para la época estudiante de segundo año de derecho, Roberto Gamboa:

La militarización de la universidad [...] hasta ese momento la entrada de la fuerza pública a una universidad, era una herejía, a partir de ese momento no, pero costo una parálisis de la universidad que se prolongó durante casi todo el año setenta y uno, costo que el rector navarro patrón entrara a la universidad no solamente con dos escoltas armados, sino el mismo armado con un treinta y ocho, ¡no sé si te han dicho eso! Armado con un revolver treinta y ocho largo al cinto, así entraba subía. Estos balcones llenos de policías con equipos antimotines, para la época eran más modestos, no era más que el casco y el escudo, en la puerta de la rectoría dos agentes del DAS armados y el rector revolver al cinto $\operatorname{armado}^{24}$.

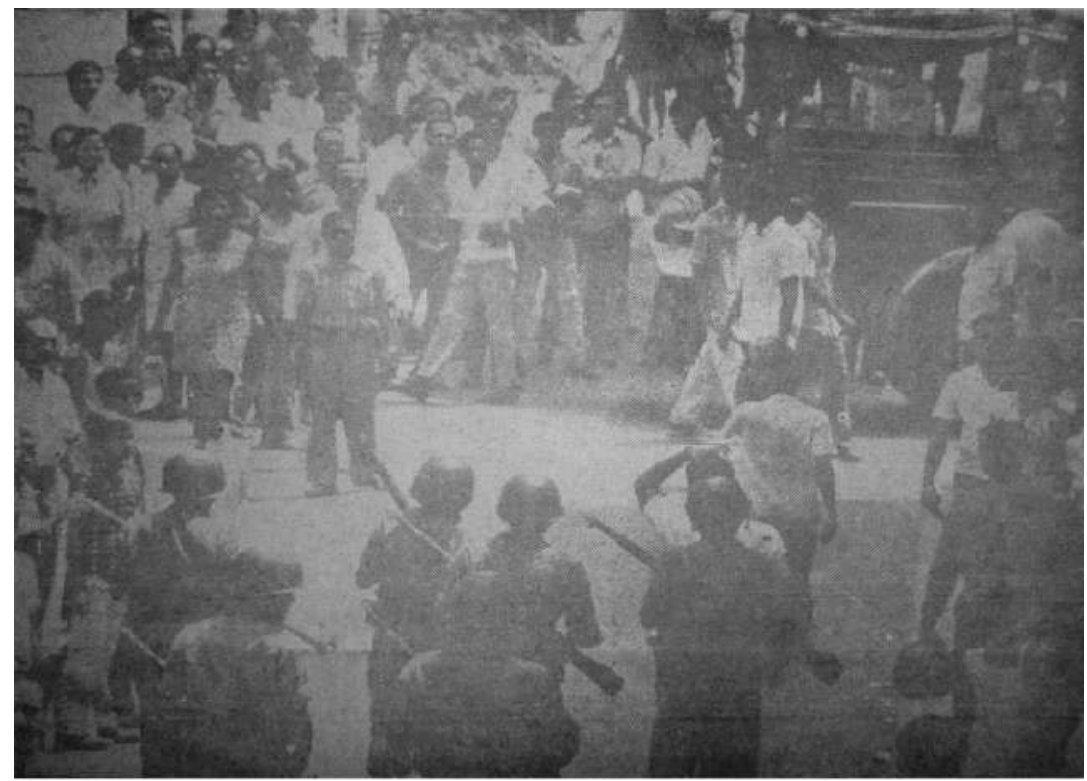

Foto. Marrugo. "Calma tensa en la universidad", AEU, El Universal, julio 8 de 1971. Enfrentamiento entre estudiantes y fuerza militar a las afueras de la Universidad de Cartagena.

${ }^{23}$ Carlos Mouthon Lorduy, Cartagena, 8 de agosto 2012.

${ }^{24}$ Roberto Gamboa, Cartagena, 30 de julio 2012. 


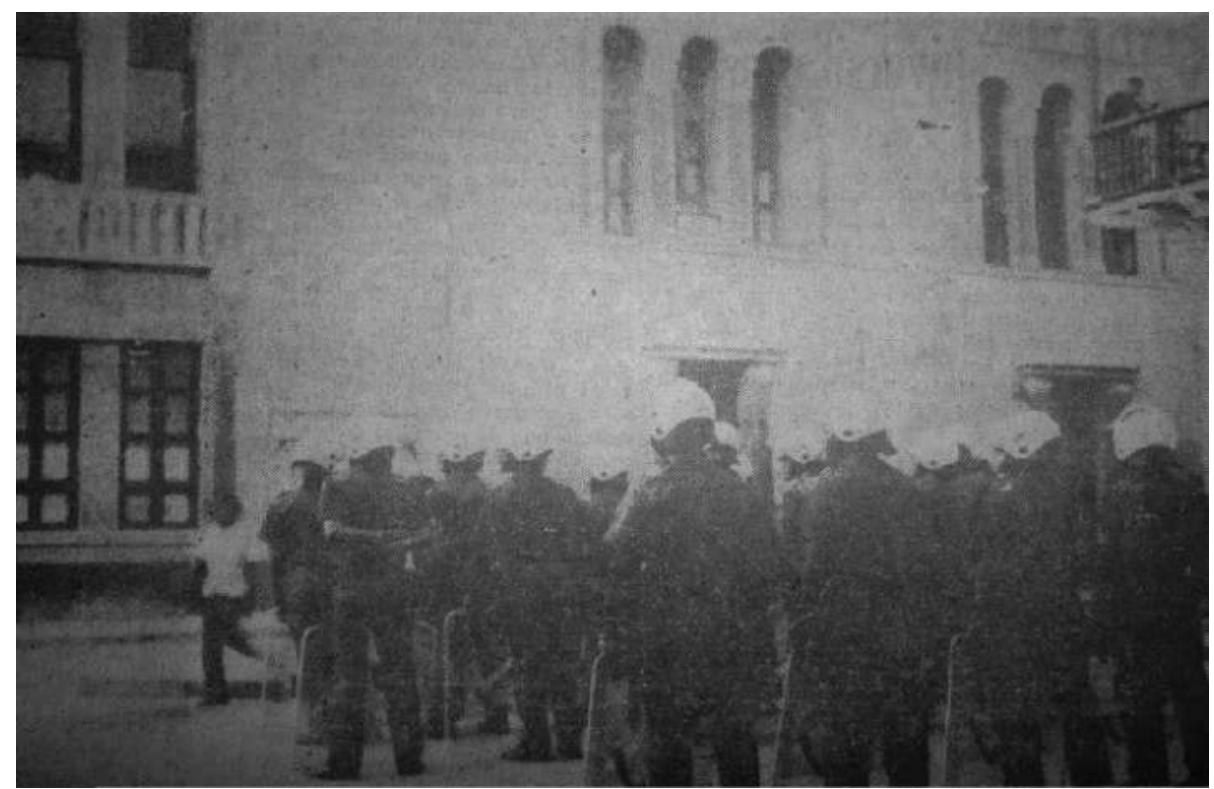

Foto. Dagut. "La universidad enfrente a grave etapa de crisis", AEU, El Universal, octubre 21 de 1971. Policías apostados a las afueras de la universidad.

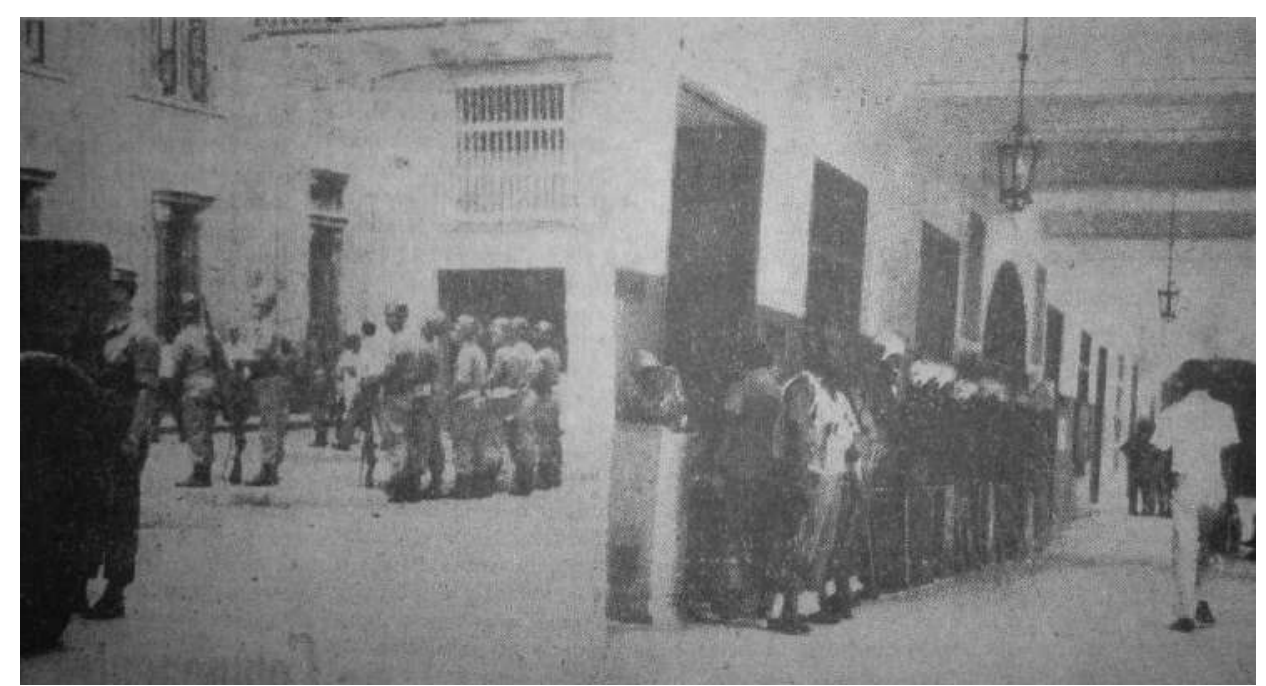

Foto. Dagut. "La tropa ocupa la universidad", A.E.U, El Universal, octubre 29 de 1971. Militares a las afueras y los pasillos de la universidad de Cartagena.

La militarización de la universidad no solo controlaba a los alumnos, y servía para desarticular paulatinamente a los integrantes del movimiento estudiantil, sino además limitaba el espacio y la movilidad de toda la población al interior del alma mater. Esto es de suma importancia, ya que no solo se quería mantener sometido al movimiento como tal, sino también se intentaba implementar medidas disciplinarias que por medio de la fuerza controlara las concepciones, las ideas y los cuerpos, este último como resultado precisamente de aquella movilidad reducida. Si tomamos en cuenta que aquellas medidas también eran implementadas para la época en casi todas las universidades del país, se puede recrear una imagen más exacta de los acontecimientos surgidos durante ese año. 
Al igual que con el medio local, los estudiantes constituyeron su propia percepción de los hechos nacionales, consecuencia de la comunicación que se estableció con el movimiento de carácter nacional y, las experiencias de estos y algunos profesores en encuentros y eventos de carácter más amplio. Tales percepciones coincidían en muchos rasgos con los que podían encontrarse de eventos de la ciudad; el uso excesivo de la violencia por la fuerza pública era bajo los dos contextos el factor más criticado. Con respecto a ello Jorge Valdelamar que para ese entonces era el profesor del área de Humanidades en la Universidad de Cartagena menciona lo siguiente.

\begin{abstract}
El movimiento estudiantil recibió una represión poco conocidas en este momento, por cuanto que la estructura del Estado utilizó mecanismo de violencia, por ejemplo perros amaestrados, caballos amaestrados, invasiones a las universidades; la entrada aquí, en Cartagena entro la fuerza pública a la Universidad de Cartagena, entró la militarización de la universidad; la universidad nacional de Colombia con la penetración de la, en la universidad nacional de la fuerza del estado en las residencias estudiantiles, entonces eso creó realmente una situación muy difícil para el movimiento estudiantil, que frente a la represión tuvo que a veces en determinado momento replegar la acción ${ }^{25}$.
\end{abstract}

Este elemento acabó determinando las concepciones de miedo y repudio hacia la fuerza pública y las autoridades institucionales, las cuales se formalizaron entonces entre los estudiantes como representaciones o elementos característicos de aquel periodo.

Conjuntamente, los encarcelamientos se constituyeron, al igual que los despidos y las militarizaciones, en piezas irremplazables de la memoria y las representaciones. Comunes luego de los encuentros entre los estudiantes y la fuerza pública o de las redadas puestas cerca de la universidad, en los acordonamientos en las áreas circundantes a la institución. Eran apresados por cometer actos catalogados como perturbadores del orden público, protestas, manifestaciones públicas, destrucción de la propiedad privada entre otros. De aquellas experiencias los jóvenes construyeron sus propias impresiones y al igual que con otros medios de control, criticaron de manera airada dichos sucesos. Carlos Mouthon estuvo apresado bajo una sentencia de casi dos meses que no se cumplió, el presenta este episodio convertido en anécdota de la siguiente manera.

En la cárcel al comienzo cuando a uno lo cogían lo agarraban, le daban a uno sus puñitos, pero ya en la cárcel bien y los presos con uno bien, y lo ponía a uno no en los patios donde estaban los bandidos grandes, una vez también la primera vez que a nosotros nos detuvieron, nos seleccionaron a tres estudiantes y los llevaron para el Carmen de Bolívar y nadie sabía en donde estábamos nosotros, entonces “desaparecidos" “¡los desaparecieron!” “¡los desaparecieron!”; la policía nos cogió, nos llevó a San Diego, nos sacaron, nos dieron un

${ }^{25}$ Jorge Valdelamar, Cartagena, 11 de julio 2012. 
poco de vueltas en la ciudad, después nos montaron en un camión y nos llevaron a la cárcel del Carmen de Bolívar hay nos tuvieron aislados como tres, cuatro días, hasta que por fin en el Carmen de Bolívar un profesor alguien le dijo que estaban unos muchachos presos, y fue como se dieron cuenta que estábamos en el Carmen de Bolívar ${ }^{26}$.

La declaración nos ofrece la posibilidad de percibir dinámicas singulares de la experiencia carcelaria, el bienestar parcial del estudiante dentro de las cárceles, las tácticas y ejecución de los estamentos de control cuando los apresaban, y ante todo un tono de desespero y angustia causada por la presunta desaparición de aquellos estudiantes, esto último es la acusación plasmada dentro de la memoria de quien fue apresado y muy seguramente de quien lo conocía; la posibilidad de una desaparición por tanto se constituyó en otro elemento que complementa una imagen del Estado y la administración de los centros educativos, en la que es posible cualquiera situación de opresión, que junto a hechos de persecución y violencia configuraron un entorno de miedo en el que pudieron vivir muchos integrantes del movimiento.

Todos estos fueron motivos internos que mantenían las discordias y pugnas; si a eso le agregamos la condición inestable de la educación superior en el país para el año de 1971, además de las circunstancias internacionales que muestran una dinámica estudiantil importante ya desde algunos años atrás, con el caso de mayo del 1968 hecho que muchos entrevistados consideraron de gran influencia para Cartagena; ${ }^{27}$ podremos entender por qué los estudiantes se amotinaron en la universidad y colegios, salieron a las calles, colocaron panfletos, realizaron mítines y construyeron discursos en torno a los reclamos.

Entre los reclamos encontramos las decisiones legislativas basadas en el plan básico de educación, como fue el proyecto de reforma educativa de 1971, siendo a su vez derivados del plan ATCON de educación dentro del marco de la alianza para el progreso. Para diversos sectores de la población estudiantil todo ello traería consecuencias negativas en el plano formativo, puesto que asumían las propuestas del estado como un intento por tecnificar muchas carreras profesionales, como medio para ofrecer mano de obra a la industria nacional, la eminente privatización de las universidades públicas, además de auspiciar la inversión estadounidense en la educación superior y una pérdida de la autonomía universitaria, elementos que fueron motivos de fuertes críticas $^{28}$.

\footnotetext{
${ }^{26}$ Carlos Mouthon Lorduy, Cartagena, 8 de agosto 2012.

${ }^{27}$ Varios de los entrevistados entre los que fueran para ese tiempo estudiantes de derecho. Roberto Gamboa, Andrés Pérez Batista y Carlos Mouthon aseguran que este fue un importante evento que los influencia y motivo para realizar las manifestaciones.

${ }^{28}$ Véase: "proyecto de plataforma de la organización estudiantil. presentado por el comité preparatorio del congreso nacional estudiantil", octubre 16 de 1970. http://es.scribd.com/doc/52353499/Proyecto-de-Plataforma-de-la-OrganizacionNacional-Estudiantil 25/10/2012; "Reportaje con Marcelo Torres, Principal dirigente del Movimiento Estudiantil de Colombia en 1971". http://www.juventudpatriotica.com. 25/ nov./2012 25/10/2012.
} 
Debido a ello, muchos estudiantes en su mayoría universitarios daban a conocer sus posturas mediante protestas, convertida en su forma de representación social por excelencia, además de charlas en diversos medios de trasportes, barrios de las ciudades, plazas públicas, colegios; acompañadas de creación de panfletos, grafitis y otros dispositivos que sirvieran para expresar lo que querían decir a la sociedad ${ }^{29}$. El elemento que encarnó en sí mismo la condición de lucha, fue el escrito denominado "Programa mínimo de los estudiantes colombianos", creado como respuestas a las reformas educativas propuesta por el gobierno. Este programa mínimo fue promulgado a través de las diferentes delegaciones que se reunieron en el III encuentro, de allí fue repartido en cada una de las universidades que se acogieron al movimiento ${ }^{30}$. (Ver anexo 1)

En contraste con todas las anteriores características, otros sectores del estudiantado no estaban a favor del movimiento de $1971^{31}$, y por el contrario apoyaban a los partidos tradicionales y las políticas del gobierno o no compaginaban con las acciones de hecho implementadas en su momento por el movimiento estudiantil, y a otros simplemente les era indiferente. Y es que debe entenderse que el contexto no pudo ser homogéneo y constante, por el contrario, las aristas lo definen como un ambiente en franca disputa, que brinda un panorama más variado de las circunstancias de la época ${ }^{32}$, en donde los antagonismos son el componente de mayor frecuencia y los altercados entre colectivos de alumnos prefiguraban movimientos y grupos heterogéneos.

A la par de las condiciones políticas, social y las movilizaciones estudiantiles, otro elementó importante que caracterizó el contexto fueron las manifestaciones culturales. Acompañado de todo el entorno conflictivo el plano de lo cultural completaba el engranaje de la dinámica del descontento. Poesía, teatro, cine, comidas comunitarias, maratones de chistes, sancochos de olla ${ }^{33}$, amenizaban las jornadas en que los estudiantes permanecían dentro de las instituciones planeando las formas en que actuarían los próximos días ${ }^{34}$. A grandes rasgos, podemos señalar que el contexto local cartagenero y universitario no es más que la confluencia de sucesos que al ser influenciados por la situación nacional e internacional, tomaría un carácter propio debido a las problemáticas particulares. La intervención estatal en la educación y las directivas educativas, casos de corrupción, relaciones entre estudiantes de diferentes establecimientos, así como un disgusto generalizado por algunos sectores de la sociedad, delimitaron la condición del año de 1971 y el movimiento estudiantil de la ciudad.

\footnotetext{
${ }^{29}$ Carlos Mouthon Lorduy, Cartagena, 8 de agosto 2012.

${ }^{30}$ Véase: "programa mínimo de estudiantes colombianos", http://es.scribd.com/doc/52353497/Programa-Minimo-de-losEstudiantes-Colombianos 25/10/2012; Isabel Hernández, "Programa mínimo", pp. 29-57.

${ }^{31}$ Véase: "El movimiento feminista en la universidad", en AEU, El Universal, Cartagena, marzo 13 de 1971 y "Verdades de una valerosa juventud feminista", en BNC, Diario de la costa, Cartagena, marzo 13 de 1971.

32“"Más sobre el nuevo movimiento de la juventud democrática”, en BNC, Diario de la costa, Cartagena, mayo 14 de 1971.

${ }^{33}$ Caldo espeso al que se le agregan ingredientes como legumbres, papas, verduras, yuca, especias, y carnes. Muchas veces se usan en acontecimientos público y sirve para alimentar a gran cantidad de población.

${ }^{34}$ Carlos Mouthon Lorduy, Cartagena, 14 de enero 2020.
} 


\section{El universo de la protesta}

Los hechos del movimiento estudiantil más allá de ser una simple dinámica de la protesta, era todo un universo en el que se configuraron las características y el carácter distintivo de los hechos. Los encuentros y plenum estudiantiles, las reuniones en que se preparaban los implementos de las manifestaciones, las charlas en diferentes partes de la ciudad, la relación entre colegios y universidades, las dinámicas culturales, la toma de la institución, son elementos que recrean este universo. Todo esto llevado a su vez por las convicciones e ideas que motivaban a los jóvenes a partir hacia la lucha; con respecto a esto el exdirigente estudiantil Carlos Mouthon Lorduy en la entrevista que ofreció, señala algunos elementos que explican este punto.

Nosotros nos percibíamos como unas personas comprometidas con una causa de cambio, una causa revolucionaria que pensábamos que realmente la sociedad tenía que cambiar, y la única forma de cambio era a través de una revolución armada [...] nosotros nos percibíamos así, nosotros nos veíamos como unos jóvenes luchadores por un cambio por la reivindicación política social del pueblo colombiano, así nos veíamos y así actuábamos ${ }^{35}$.

Palabras de este tipo nos colocan de frente con una concepción que acerca a los estudiantes a una condición en que su tarea era salvar la sociedad del declive en que se encontraba. De algún modo, la influencia de una época de cambios llevó a la consideración que solo en la transformación de la sociedad se alcanzarían los avances necesarios para un mejor futuro. Las circunstancias de opresión por las que debieron afrontar con las acciones del estado y las directivas universitarias, además de ser un aliciente para las protestas, sembraba en muchos jóvenes la idea que ellos eran los únicos capaces de resistir la situación y llevar a cabo ese cambio social.

Es así como tenían sentido actos como los encuentros y los plenum, muchas veces cometidos bajo la regulación de las autoridades universitarias y algunos tenían una resonancia a nivel local apareciendo sus fechas en periódicos de la $\operatorname{ciudad}^{36}$. Una de las características más representativas era el antagonismo entre quienes asistían, no solo de los bandos que podríamos considerar contrarios, por ejemplo, los estudiantes pertenecientes a partidos tradicionales y las vertientes marxistas, si no además, por parte de los que compartían posiciones ideológicas. Las arduas conversaciones se extendían hasta altas horas de la noche, y se tomaban decisiones en cuanto a la programación de los paros de actividades académicas, toma de la universidad, orientaciones ideológicas, propuestas para actividades fuera y dentro de la institución y posiciones en cuanto a los hechos nacionales y locales. De tal manera lo describe Andrés Pérez Batista: "Fueron muy famoso los plenum como los

${ }^{35}$ Carlos Mouthon Lorduy, Cartagena, 8 de agosto 2012.

36 "Plenum universitario próximo jueves", en AEU, El Universal, Cartagena, febrero 24 de 1971. 
llamábamos, que hacíamos en el aula máxima y en el paraninfo de la Universidad de Cartagena, que era donde se daban debates de carácter ideológico de mucha altura $\mathrm{y}$, donde brillaban muchas inteligencias de estudiantes vinculados al movimiento que eran de diferentes facultades" 37 .

Por otra parte, de manera informal las reuniones de pasillo eran más frecuentes, aquí se fabricaban los implementos que utilizaron en las protestas o se acordaban las maneras en cómo se llevarían las charlas a diferentes sitios de la ciudad y otras instituciones. Comúnmente se sentaban en los salones o pasillos, junto a metros de telas y pintura con la cual escribirían los panfletos llenos de mensajes con los nombres de los movimientos o semestres que marcharían. En muchas ocasiones, al igual que en los plenum se encontraban estudiantes de colegios de la ciudad principalmente del Liceo de Bolívar, que mantenían una relación estrecha con los estudiantes de la universidad muchos de los cuales eran bachilleres de esta institución.

Luego de los encuentros uno de los puntos más importantes era la reproducción de las decisiones y la posición tomada por el movimiento. De tal manera que las charlas en lugares públicos se convirtieron en una herramienta indispensable las plazas, colegios, medios de trasporte como buses, eran los habitualmente escogidos para este fin. A su vez los grafitis y pancartas colocados en algunas paredes de la ciudad y la universidad, llevaban mensajes en donde se mostraba la posición adoptada por los estudiantes ante temas que consideraban de importancia.

El movimiento estudiantil primero comenzó con las expresiones propias de los estudiantes, murales, carteles, mítines dentro y fuera de la universidad, porque yo creo que fue por primera vez que se trató de sacar el movimiento estudiantil de la Universidad de Cartagena para que la población de Cartagena entendiera que había una universidad [...] entonces uno se desplazaba a diferentes barrios para llevar, como dice uno, sacar el movimiento de las paredes de la Universidad de Cartagena $^{38}$.

Acompañado de todos aquellos elementos, el entorno cultural casi carnavalesco se convirtió en otro componente importante dentro del universo del movimiento estudiantil. El escenario mostraba no solo la protesta o los encuentros formales para la ejecución de las actividades plenamente académicas u bajo una orientación político-social, las actividades culturales eran sin lugar a duda un punto importante en la vida misma del quehacer estudiantil. Presentaciones de los cineclubes, muestras teatrales del TEUC ${ }^{39}$ y el Teatro estudio Liceo de Bolívar, cuenta cuentos, maratones de poesía, son solo alguno de las actividades que amenizaban las jornadas y prefiguran ese universo real del universitario, que en definitiva era un joven que sentía y

\footnotetext{
${ }^{37}$ Andrés Pérez Batista, Cartagena, 18 de junio 2012.

${ }^{38}$ Andrés Pérez Batista, Cartagena, 18 de junio 2012.

${ }^{39}$ Teatro Estudio Universidad de Cartagena, proyecto educativo y compañía de teatro al interior de la universidad.
} 
vivía su época. Bajo todas estas características Roberto Gamboa y Andrés Pérez Batista señalan lo siguiente.

Había un movimiento cultural permanente por iniciativa de los estudiantes y bueno con respaldo institucional [...] las jornadas en razón del activismo, de los movimientos insurgentes no había clase, se hacían veladas literarias, actividades culturales como la presentación de obras de teatro, cuentearía, lecturas de poema, interpretaciones musicales ${ }^{40}$.

En esa época se dio cabida a un excelente y extraordinario movimiento cultural, el teatro estudio de la Universidad de Cartagena como nunca, como nunca; en la Universidad Libre también surgieron grupos de teatros, grupos de poesía, surgieron grupos de danza, la actividad de títeres, de teatro, era una actividad que incluso nosotros la tomábamos como apoyo, los cineclub, era una actividad muy pero muy intensa, la pintura, literatura, poesía [...] era un movimiento cultural intenso, intenso, intenso, y con un contenido también de apoyo y respaldo a las ideas que nosotros planteábamos para ese momento, como las ideas de cambio, las ideas revolucionarias ${ }^{41}$.

Por otra parte, la estructura del movimiento estudiantil estaba compuesto por todo tipo de integrantes, en donde sobresale sin duda la participación de las mujeres como componentes dinámicos en las manifestaciones, además de las asambleas y plenum. Cabe resaltar que para 1971 también existía un movimiento de mujeres autodenominado como los feministas, pero estas eran detractoras del movimiento estudiantil ${ }^{42}$. Las jóvenes se articulaban plenamente como cualquier otro integrante, pero además existieron figuras significativas como la de Martha Sierra, quien es reconocida en muchas de las entrevistas y a la cual se le realizó un homenaje con la elaboración de un escrito denominado "Marta Sierra: ninguna de nosotras camina sola" 43 , en el que se narra parte de su vida como activista. Al tiempo existen remembranzas de la participación femenina y su injerencia, en anécdotas que narran los entrevistados.

Había muchas [...] que participaban ideológicamente y activamente [...] Tuve la experiencia de verlas llevar las piedras en los bolsos, y bueno la fuerza pública en ese entonces era como mucho más caballerosa ¿no? Entonces a la mujer ningún policía se atrevía a tocarla ni a requisarla, ella llevaban las piedras y los muchachos se encargaban de levantar a piedra las vidrieras de los almacenes del centro ${ }^{44}$.

Pero la declaración anterior no solo hace referencia a la participación femenina, puesto que deja a la luz otro elemento no menos relevante, como

\footnotetext{
${ }^{40}$ Roberto Gamboa, Cartagena, 30 de julio 2012.

${ }^{41}$ Carlos Mouthon Lorduy, Cartagena, 8 de agosto 2012.

42 Véase: "El movimiento feminista en la universidad", en AEU El Universal, Cartagena, marzo 13 de 1971.

${ }^{43}$ Giobanna Buenahora, "Marta Sierra: ninguna de nosotras camina sola". Poligramas. Cali: Univalle, 2010, pp, 68-75. http://poligramas.univalle.edu.co 25/10/2012

${ }^{44}$ Roberto Gamboa, Cartagena, 30 de Julio 2012.
} 
eran los desórdenes públicos causados por los jóvenes estudiantes. Aquellos hechos también poseen su propio espacio en las representaciones constituida de las memorias de los participantes, actos considerados como vandálicos por las autoridades estatales, complementaban las condiciones específicas del momento, y se constituyeron de algún modo como una característica por la cual se identificaba a los estudiantes y al movimiento en general. Sin lugar a duda, este componente es crucial para la posterior identificación del joven bajo esa imagen de revolucionario que hasta la actualidad se mantiene y se afianzó bajo aquella coyuntura, la cual se refiere a la relación de los jóvenes estudiante de universidades públicas y la incursión de muchos de estos al ámbito de la lucha armada en las guerrillas, algo que se generalizaría en las décadas posteriores ${ }^{45}$.

Toda esta vida dentro de la dinámica del estudiante que protestaba no ha sido estudiada a profundidad y se constituye en uno de esos vacíos que no deja percibir su figura totalmente, en ese andar cotidiano que lo catapulta como los jóvenes que promulgaba por cambios sociales, políticos y culturales a veces utópicos. Pero todo este universo no estaría completo sin los fundamentos e ideales que le dieron sentido. Es aquí donde los principales idearios que plagaban concepciones de los estudiantes constituían todo un imaginario, en donde sus representaciones fueron esculpidas según las figuras que para ellos eran los más trascendentales de la época, además de las lecciones aprendidas a través de la investigación y el estudio de temas como el marxismo y la política. Se consolidaron entonces sucesos y procesos como la revolución cubana o mayo del 68, igualmente personajes como: Ernesto Guevara, Camilo Torres, Mao Zedong, Lenin, Daniel Cohn-Bendit más conocido como Daniel el rojo, en elementos que no solo oscilaban dentro de las representaciones establecidas en la juventud estudiantil, sino que se convirtieron en componentes que representaban al movimiento estudiantil en sí mismo.

\section{Las figuras del movimiento estudiantil}

La apropiación de figuras que se asumen como representaciones en los movimientos estudiantiles de finales de la década de 1960 e inicios de la década de 1970, resultan un componente generalizado a lo largo de las diversas manifestaciones sociales alrededor del mundo. Una de las representativas es Ernesto Guevara, adoptado desde el mayo francés, pasando por el México de ese mismo año, hasta nuestro contexto de estudio Cartagena. Este proceso resulta de la asimilación de los jóvenes en este contexto de cambio en dicha coyuntura; de modo que las representaciones que estos construyeron se vinculan a las concepciones ideológicas aceptadas y apropiadas a través del tiempo, que empleaban para sustentar sus acciones y

\footnotetext{
${ }^{45}$ Álvaro Acevedo y Gabriel Samacá Alonso, "Entre la movilización estudiantil y la lucha armada en Colombia. De utopías y diálogos de Paz". Anuario de Historia Regional y de las Fronteras, 20, 2, (2017): 157-182. http://dx.doi.org/10.18273/revanua.v20n2-2015006 20/04/2017
} 
la identificación de elementos icónicos en los que se vieron representados como movimiento.

De esta manera, las ideologías marxistas sería el componente asimilado más importante, entendiendo que bajo el telón de la guerra fría fluctuaban alrededor del globo, por una parte ideas ligadas al socialismo y el comunismo impulsadas por la Unión Soviética y China, y por otro, las capitalistas promulgadas por los Estados Unidos y algunos países de occidente. Por ello la penetración de dicho proceso puede percibirse por la aceptación o desprecio, que este causó dentro de la población estudiada.

Cabe aclarar que las concepciones marxistas ya habían penetrado la universidad y algunos colegios desde hacía ya décadas, así nos lo hace saber Amalfi Padilla quien realizó algunos trabajos en torno a las relaciones de poder dentro de la Universidad de Cartagena para la segunda mitad del siglo $\mathrm{XX}^{46}$. De esta manera para el caso preciso de 1971, el hecho que mayor impacto tuvo dentro de los círculos académicos fue la revolución cubana, la cual, para muchos fuera el ejemplo más deciente de la consolidación de un estado de ala izquierda en la región. Por esas características se convirtió en un estado visto como utópico y ejemplo de una construcción social que produjo ante todo un modo de vida diferente y favorable. Pese a que este acontecimiento se presentó para la década del cincuenta un poco alejado de 1971, su influencia fue directa y en vez de menguar la percepción que se tenía del mismo se fueron enriqueciendo a través del tiempo, transformando la imagen del Che Guevara en símbolo de las luchas y elemento que representará y encarnará las nociones mayormente aceptadas por un grueso número del estudiantado.

Había mucha influencia de la revolución cubana, el Che Guevara era un dios, el día que entró la fuerza pública a la Universidad de Cartagena con el nuevo rector Manuel Navarro Patrón, celebre, estábamos celebrando el día del guerrillero heroico, debió ser para la fecha que se conmemoraba la muerte reciente del Che Guevara. Y había un pendón que bajaba del tercer piso casi hasta el primer piso con una esfinge del Che Guevara, de Ernesto Guevara. Los líderes del movimiento estudiantil vestían, hablaban, pensaban y disfrutaban como el Che Guevara $^{47}$.

Entonces el Che Guevara se consolidó como referente, elemento representador y punto convergente de muchos estudiantes; por medio de su imagen se podía medir elementos como las ideas y deseos, además que encarnaba todo un estado ritual dentro de los miembros del movimiento estudiantil, en donde eventos como la conmemoración del día del guerrillero heroico redefinió de algún modo el calendario festivo habitual, ya que ese día se subvertía convirtiéndose en una fecha con una gran carga simbólica.

\footnotetext{
${ }^{46}$ A. Padilla, "Organizaciones estudiantiles”, pp. 133-134.

${ }^{47}$ Roberto Gamboa, Cartagena, 30 de julio 2012.
} 
Acompañada de la versión descrita por algunos de los entrevistados los diferentes periódicos también corroboran esta consolidación del Che Guevara como componente icónico idolatrado. "El "Che" Guevara parecía posesionado de la Universidad de Cartagena en los tres últimos días. Su esfinge se multiplicó por decenas y habito en los pasillos, escalera, aulas y en cualquier sitio dispuesto a recibir los rasgos definidos heredados de la Tricontinental de La Habana"48.

De manera paralela, este no era el único objeto de carácter icónico que diera visos de las representaciones construidas dentro del movimiento estudiantil. Puesto que el conglomerado de procesos que pudieron influenciar las ideas de los estudiantes fue variado. Entonces se constituyó un panteón de nuevos héroes, que trasgredían considerablemente a los símbolos catalogados de nacionales dentro del establecimiento de la política y la sociedad del país. Así se muestra en una fuente del Diario de la Costa citada por Amalfi Padilla en la que además de describir la situación de la universidad se señalan a muchos de estos personajes

Este viejo adagio fue puesto de moda por el nuevo rector de la Universidad de Cartagena al dictarla resolución 51 por medio del cual será sancionado con la pena de expulsión definitiva del alumno en cualesquiera de estos actos: agresión de hecho o de palabra, destrucción de los daños de elementos o bienes de la universidad, manifestaciones, motines, tumultos, la falta de respeto a las autoridades y la colocación de carteles, letreros, afiches, emblemas propagandísticos que de alguna modo tiendan al desconocimiento de la autoridades, a la comisión de delitos o a la exaltación o apología de las vías de hecho o de la violencia. [...] aquellos afiches con frases de batalla dentro de la subversión, retrato de los decadentes líderes revolucionarios en Cuba, China, Bolivia y Chile habían desaparecido, todo era resultado de la recuperación del principio de autoridad. ${ }^{49}$

Este gran conjunto de figuras, no solo eran elementos definidores de representaciones e ideales de los jóvenes, los medios de comunicación también establecieron su propia interpretación de los mismo, acusándolos de desligar a los alumnos de las concepciones establecidas bajo la construcción de una nación colombiana, puesto que la figuras de personajes ilustres de nuestra historia patria o de importancia considerable para el desarrollo intelectual del país no estaban presentes en sus afiches, grafitis y pancartas dentro de las instituciones educativas. De este modo lo muestra el Diario de la Costa.

Con el caso de haber convertido las paredes del edificio institucional en carteleras de propaganda del "Che" Guevara, y otros expoliadores de nuestras libertades democráticas. No son nuestros próceres nacionales, no las imágenes de Bolívar, de Santander -fundadores de esa

\footnotetext{
${ }^{48}$ Roberto Gamboa, "Normalidad pacifica vivió la universidad", en AEU, El Universal, octubre 9 de 1971.

${ }^{49}$ A. Padilla, "Organizaciones estudiantiles", pp. 146-147.
} 
universidad- ni siquiera la de eminentes personalidades colombianos que le han dado lustre a la cultura del país, un Caldas, un Cuervo, un Suarez y demás pléyade de fundadores de la nacionalidad, los escogidos por los ravacholistas que medran a la sombra de nuestro universitariado, para deshonrarnos en la mismo corazón de la entidad matriz comprometida a moldear la conciencia de los auténticos dirigentes futuros de la nación ${ }^{50}$.

Esta actitud, que bajo una lectura superficial podríamos considerar como antipatriótica, para nuestro análisis se convierte en la acción estudiantil, que, en aras de reivindicar sus consignas, crearon todo un escenario en que los héroes patrios son remplazados por figuras icónicas de las que se sentían identificados y, a su vez, les otorgaba un sentido como grupo organizado.

Pero no solo se consolidó la imagen de acontecimiento y personajes internacionales. Personajes como el padre Camilo Torres, había penetrado en las ideas de los estudiantes ${ }^{51}$ al punto de convertirse en otro referente que estaba paralelo a la imagen del Che Guevara, así lo menciona el investigador Álvaro Camacho: "El recuerdo que tenía el joven de Camilo y el Che asumía un efecto diferente: lejos de amilanarse, los estudiantes radicales revivían y reverenciaban la memoria de los dos luchadores, e incluso un sector guerrillero había adoptado el nombre de Camilo en su identificación" 52 .

Mucha de esta influencia es corroborada no solo por las entrevistas a estudiantes de la época, sino también, por algunas descripciones de periódicos de la ciudad que, al cubrir ciertas noticias, informaban acerca de las figuras representativas colgadas en los pasillos de la universidad y muy seguramente en otras instituciones de la ciudad y el país. Por ello, para el mes de septiembre, cuando se cubría la noticia de la renuncia de altos dirigentes de la universidad, luego de una asamblea precedida entre otros por el entonces rector Juan Carlos Arango y los estudiantes, sobresale el siguiente fragmento: "Permanecieron sentados en el proscenio del paraninfo, teniendo a sus espaldas retratos de Camilo Torres, el Che Guevara y Lenin y rodeados de consignas revolucionarias, mientras se adelantaba el debate" 53 .

Entre todo esto, los sucesos considerados de mayor trascendencia también fueron escogidos como punta de lanza y ejemplos a seguir en la lucha de los estudiantes. Pese a la distancia entre Francia y Latinoamérica, el suceso de mayo 68 tuvo un gran impacto entre los alumnos de la región y el país, así mismo en la Universidad de Cartagena y el Liceo de Bolívar. Este hecho fue visto como un aliciente que catapulto las diferentes manifestaciones en la ciudad y era de habitual conocimiento para ciertos sectores dentro del ámbito académico. Personajes como Daniel Cohn-Bendit más conocido como Daniel

\footnotetext{
50 "El vacío de autoridad", en BNC, Diario de la Costa, Cartagena, octubre 17 de 1971.

${ }^{51}$ Roberto Gamboa, Cartagena, 30 de julio 2012.

52 Álvaro Camacho, "Los años sesenta: una memoria personal". Revista de Estudios Sociales, 33, (2009): 76. http://res.uniandes.edu.co/view.php/597/view.php 18/07/2012

53 "Renuncia masiva de directivos de la U”, en AEU, El Universal, Cartagena, septiembre 8 de 1971.
} 
el Rojo, fue admirado por unos y por otros depreciado, pero reconocido a fin de cuantas. Incluso los periódicos de la ciudad no dudaban en comparar los acontecimientos recientes del país con los del mayo francés, dejando claro el parangón que desde la opinión pública se hacía con respecto a ellos.

Desgraciadamente el problema estudiantil es más de fondo que de forma. Es una acción integrada a nivel nacional de fuerzas subversivas para alterar el orden público. Es además un enfrentamiento doctrinario. Le llegó a Colombia el mes de mayo francés. Es el clásico desafío de las izquierdas extranjerizantes contra las de derechas nacionalistas. No hay menor equivocación ${ }^{54}$.

Las declaraciones en cuanto a este hecho también abundan en las palabras de los entrevistados, quienes aseguran que fue uno de los que más influencia tuvo en la población de la universidad principalmente entre diferentes dirigentes estudiantiles, y señalan la importancia como referente internacional: "En el año 68 tú sabes que hubo, el movimiento estudiantil de Francia, mayo del 68 que es cuando yo entró a la universidad, la gran mayoría el caso mío por lo menos estaba muy influenciado por el movimiento francés de Daniel Cohn-Bendit, el famoso Daniel el rojo"55.

En definitiva, la configuración de figuras icónicas se constituyeron en elementos definidores de las representación constituidas por el movimiento estudiantil, en una época que desde sus cambios también trasformó los ideales de los estudiantes, así se dio cabida a la transgresión de estamentos oficiales, como la instauración de nuevos héroes reconocibles diferentes a los héroes patrios, o la consolidación de fechas festivas que se contraponen a los fachas habituales de la festividad, y que contiene una gran carga simbólica dentro el estudiantado. Con todo ello se evidencia la penetración de ideales que bajo el contexto colombiano y Cartagenero son reinventados y a su vez les otorga el sentido primario a los hechos presentes en el año 1971.

\section{Mecanismos de difusión. Una propuesta desde el caso del Che Guevara}

Es indudable la influencia de un personaje como Ernesto Guevara en este movimiento estudiantil, por ello hemos querido tomar la figura de este personaje para desde su ejemplo rastrear los procesos de apropiación de figuras representativas para los estudiantes en esta coyuntura; y si bien no resulta el único caso relevante, si nos brinda indicios con respecto a la manera en cómo concebían su entorno y sus manifestaciones los estudiantes de Cartagena para 1971. Nuestra intención es entender a través del análisis del proceso de significación de esta figura las formas de apropiación y definición de esté, que brinda la posibilidad de ilustrar sobre las formas de adopción, los valores, creencias y juicios, que algunos estudiantes construyeron dentro de su experiencia en el movimiento.

\footnotetext{
${ }^{54}$ Pedro de arenal y soplaviento, "Inquietudes", en BNC, Diario de la Costa, Cartagena, octubre 17 de 1971.

${ }^{55}$ Andrés Pérez Batista, Cartagena, 18 de junio 2012.
} 
Las formas de apropiación de la figura del Che en Cartagena esta mediado por las condiciones espaciales y temporales, en dónde los estudiantes cargan de significaciones y valores determinados, de acuerdo con las condiciones de sus luchas y los intereses que tienen. Es así como por medio de los recuerdos de los participantes, pueden distinguirse componentes que hacen parte de una red compuesta por diversos componentes, que hizo posible un mayor conocimiento sobre el personaje del Che y la revolución cubana en los estudiantes.

De esta manera, podemos ver cómo la circulación de saberes entorno a estos personajes al interior de un movimiento estudiantil, nos arroja un primer componente como son los textos escritos, que hablen sobre él y la revolución cubana, es de esta manera que textos como el Diario del Che y otros escritos que provenían de Cuba y que tuvieron un fuerte impacto en los estudiantes, como eran las revista Bohemia y el Granma, se convirtieron en piezas fundamentales que hacían referencia al personaje del Che, "recuerdo 2 revistas una era el Granma y la otra bohemia, no recuerdo cómo llegaba a mis manos, pero si llegué a tener varios ejemplares, esas venían de Cuba"56.

En Cartagena la muerte del Che ya había ocurrido algún tiempo atrás, y los escritos entorno a su pensamiento eran más numerosos y de gran difusión, la elaboración de escritos por parte de imprentas clandestinas de los estudiantes y colectivos de izquierda, permitieron el acercamiento cada vez mayor de estos jóvenes a este y otros personajes del momento Iósif Stalin, Mao Zedong, Fidel Castro, Hồ Chí Minh, Lenin, así como ideas principalmente de izquierda que circulaban derivadas de escritos provenientes de China, Cuba o Rusia. Con respecto a la difusión de textos, Carlos Mouthon nos dice lo siguiente.

Había algunos textos que circulaban entre nosotros, principalmente entre los chicos que eran militantes, y que también, se encontraban dentro del movimiento estudiantil, El Diario del Che, era uno de estos. Recuerdo que a veces circulaban y hablamos de ellos, eso era importante, porque tú tenías que saber, tenías que entender cómo era la lucha" $"$.

De esta manera, se puede ver como el componente escrito configuró una de las maneras de acercarse al Che, y de este mismo modo ayudo a estructurar una memoria cargando de significaciones que hizo posible las readaptaciones por parte de los estudiantes, para consolidar su propia memoria del personaje, presente en los recuerdos y remembranzas sobre este símbolo.

Otro componente no menos importante, es la radiodifusión de la radio cubana que para el caso cartagenero juega un papel de primer orden al momento de estudiar la consolidación del símbolo del Che, presente en el movimiento estudiantil. Todo esto se evidencia en declaraciones como las de Roberto

${ }^{56}$ Roberto Gamboa, Cartagena, 10 de enero 2020.

${ }^{57}$ Carlos Mouthon Lorduy, Cartagena, 8 de agosto 2012 
Gamboa quien menciona lo siguiente, "Recuerdo que yo tenía un radiecito de transistores, en se podía sintonizar algunas frecuencias lejanas, ya no se puede hacer, en ese tiempo si, incluso en algún momento llegué a escuchar radio de Estados Unidos, en esa radio que yo tenía podía escuchar música y muchas cosas de otras partes también de Cuba"58. De modo que la radio y su impacto en la escena del movimiento estudiantil cartagenero, está marcada por una facilidad y masificación de la radio cubana en este contexto; de manera que el estudiantado compartió rasgos de esa influencia con el resto de la población de la ciudad, pero a su vez, un acercamiento distintivo que lo vinculo al escenario político cubano, que le será útil de acuerdo con sus intereses particulares en su lucha.

Dentro de esta red de circulación de informaciones, el componente de voz a voz es el catalizador de los usos que se le dio a la figura del Che Guevara, convirtiéndose en un punto central dentro de la apropiación del personaje y construcción del símbolo. A través del diálogo continuo entre estudiantes, grupos de estudiantes, los estudiantes de diversas facultades, asambleas y medios como pancartas, pendones, canciones, poemas, panfletos se trasmite el sentido de la protesta y la lucha, además que se articula el movimiento estudiantil, y por supuesto, se significa al Che Guevara que pasa de figura a símbolo.

Es aquí donde la figura del Che, es retomada, significada y convertida en símbolo de acuerdo a los intereses particulares, cargada de valores y atributos, y puesto al servicio del estudiante que se siente representado por este personaje. En esta parte del proceso de difusión el contexto marca lo que se va a decir y asimilar de esta figura.

Componentes como el compañerismo, la experiencias en la protestas, los diálogos, los panfletos y acciones de propaganda dentro del movimiento, las reuniones de pasillo, los grupos pequeños de trabajo dentro de la organización de movimiento, unido a la movilidad e interacción que permitió el escenario de huelga, perceptible en las relaciones instauradas entre personas de diversidad facultades, géneros y cargos dentro de las universidades, se convirtieron en componentes de vital importancia a la hora de comprender la apropiación y significación del símbolo del Che Guevara para el escenario cartagenero.

Si ves este cuadro que está aquí en medio de la plaza, bueno aquí había un farol, nosotros siempre nos acercábamos cuando estábamos en el 71, llegamos aquí empezamos a charlar la gente empezaba a llegar, y así mismo, se hacían asambleas relámpago, aquí nos encontramos todos y como la universidad no tenía más sedes en ese tiempo, pues toda la comunidad se conglomerado aquí, todo nos veíamos, incluso los que antes no sabíamos quienes éramos ${ }^{59}$.

\footnotetext{
${ }^{58}$ Roberto Gamboa, Cartagena, 30 julio de 2012.

${ }^{59}$ Carlos Mouthon Lorduy, Cartagena, 8 de agosto 2012
} 
Estás dinámicas fueron posibilitando la emergencia de figuras que fueron tomadas como referentes de lucha, que de manera casi ritual a partir de las dinámicas propias de los salones, movilizaciones y asambleas; estructurando una especie de propaganda en la cual aparecía ya convertido en símbolo el personaje del Che Guevara, con adeptos que para Cartagena poseía pendones de 5 metros de altura, frente a la entrada principal al interior de la plaza central del Claustro de San Agustín.

Esa gente estaba como endemoniada, yo recuerdo una vez, yo no quise ser parte de ese movimiento, porque un día iba pasando por el pasillo que queda saliendo como el que va para la plaza dentro del claustro de San Agustín, y sin culpa, sin saberlo, se cayó un pendón inmenso que había colgado con la imagen del Che dentro de la universidad, cuando veo que esa cosa se viene para abajo, y pensé, se cayó sin culpa, cuando es que antes de yo darme cuenta estoy rodeada de un poco estudiante fanáticos seguidores del Che, que me estaba reclamando, por qué había tirado ese pendón, y si no es porque una prima también estaba con ellos, a mí me hubieran echado cola de esa qué sirve para pegar papeles en las paredes, en mi pelo, me hubieran dañado toda mi cabeza ${ }^{60}$.

De esta manera se fueron estructurando apelativos referentes a la figura del Che en cada escenario para los estudiantes de Cartagena van a guardar una relación vinculada a la figura antimperialista, como ejemplo a seguir y mártir, un sujeto que promulgaba por la resistencia y el cambio desde la presentación de sus propias vidas por ese cambio, establecida más ampliamente por las confrontaciones con la política de educación que desde EE. UU se querían imponer en el país.

\section{Conclusión}

A manera de conclusión podemos señalar que las características del movimiento estudiantil en la ciudad de Cartagena, poseen pormenores debido a las circunstancias del contexto marcado por problemáticas como, la incursión de El barco Hope, y quizás más importante, la llegada personaje como Manuel Navarro patrón, personaje preponderante en la consolidación y ejecución de un sistema de operación a la población estudiantil y profesoral que estaba a favor de la lucha de los estudiantes. Asimismo, se muestran algunos puntos como la heterogeneidad de los estudiantes, las disputas antagónicas entre muchos de los grupos que están a favor y en contra del movimiento estudiantil, la consolidación de todo el universo en el cual no solamente la protesta, sino las vinculaciones, lazos y relaciones entre estudiantes, fluctuaban como punto central de la configuración de un movimiento estudiantil que se sostuvo por gran parte del año 1971, la configuración de un conjunto de figuras tomadas como representativas para estos mismos estudiantes que establecieron una especie de panteón de héroes, con los cuales, estos se sentían identificados y finalmente el proceso de

${ }^{60}$ Patricia Bermúdez, Cartagena, 9 de octubre 2012 
apropiación de personajes por parte de los estudiantes como es el caso de Ernesto Guevara, se hacen presente en este estudio para complementar no sólo las condiciones del movimiento estudiantil en la ciudad de Cartagena, sino además ofrecer una propuesta en la que muchas de estas condiciones y características, ofrecen posibles indicios de otros contextos en donde el esta dinámica estudiantil tuvo cabida en 1971.

Más allá de considerar el presente texto como la última palabra con respecto a este tema, procuramos ofrecer un aporte qué busca recabar y encender esa chispa qué procure una mayor producción historiográfica en torno a la temática del movimiento estudiantil, demostrando como los diferentes contextos del país brindan aportes valiosos para una visión mucho más amplia y concreta de los sucesos ocurridos hace ya más de 50 años en Colombia.

\section{Bibliografía:}

\section{Fuentes primarias:}

Archivo Universidad de Cartagena (Cartagena-Colombia), Sección Resoluciones de rectoría, Volumen Septiembre-Diciembre 1971, números: 524 19-10-1971, 525 20-10-1971, 536 22-10-1971, 53925 -10-1971, 543 26-10-1971.

Biblioteca Nacional de Colombia (BNC), Diario de la Costa, Cartagena, 1971.

Archivo de El Universal (AEU), El Universal, Cartagena, 1971.

Camus Frank, "Paradojas", en Archivo El Universal (en adelante A.E.U.), El Universal, Cartagena,17 febrero de 1971.

Biblioteca Bartolomé Calvo (BBC), Diario de la Costa, 1971.

\section{Entrevistas}

Andrés Pérez Batista, Cartagena, 18 de junio 2012.

Carlos Mouthon Lorduy, Cartagena, 30 de julio 2012.

Carlos Mouthon Lorduy, Cartagena, 14 de enero 2020.

Jorge Valdelamar, Cartagena, 11 de Julio 2012.

Patricia Bermúdez, Cartagena, 9 de octubre 2012.

Roberto Gamboa, Cartagena, 30 julio de 2012.

Roberto Gamboa, Cartagena, 10 de enero 2020. 


\section{Fuentes secundarias:}

Acevedo Tarazona, Álvaro, Modernización, conflicto y violencia en la universidad en Colombia: AUDESA, 1953-1984, Bucaramanga, UIS, 2004.

Acevedo Tarazona, Álvaro, "Educación, reformas y movimientos universitarios en Colombia: apuestas y frustraciones por un proyecto modernizador en el siglo XX". Revista de Estudios Sociales, 53, (2015): 102-111. http://dx.doi.org/10.7440/res53.2015.08 20-12-2017

Acevedo, Álvaro y Samacá Alonso, Gabriel, "Entre la movilización estudiantil y la lucha armada en Colombia. De utopías y diálogos de Paz". Anuario de Historia Regional $y$ de las Fronteras, 20, 2, (2017): 157-182. http://dx.doi.org/10.18273/revanua.v20n2-2015006 20/04/2017

Aranda, José María, "El movimiento estudiantil una teoría de los movimientos sociales". $\quad$ Convergencia, 21, 225-250. http://convergencia.uaemex.mx/rev21/pdf/aranda.PDF 17/08/2012

Buenahora, Giobanna, "Marta Sierra: ninguna de nosotras camina sola", en, Poligramas. Cali: Univalle, 2010, pp, 68-75. http://poligramas.univalle.edu.co $25 / 10 / 2012$

Camacho, Álvaro, "Los años sesenta: una memoria personal". Revista de Estudios Sociales, 33, (2009): 70-78. http://res.uniandes.edu.co/view.php/597/view.php $\underline{18 / 07 / 2012}$

Camarena, Ocampo Mario (coord.), La construcción de la memoria colectiva. México: Instituto Nacional de Antropología e Historia/Escuela Nacional de Antropología e Historia/Concejo Nacional para la Cultura y las Artes, 2010.

Camarena Ocampo, Mario y Martínez Guzmán, Rocío, "Memoria de un proyecto comunitario: tejiendo testimonios". Diario de campo 9. México: INAH, 2015, pp. 60-66.

Fariñas Lázaro, Díaz, "A cincuenta años de la alianza para el Progreso: el debate por el socialismo”. Economía y Desarrollo, 149, 1, (2013): 139-157.

Garay Arellano, Graciela de, "De la palabra a la escucha. Una reflexión sobre la legitimidad del testimonio oral", en Graciela de Garay Arellano y Jorge Eduardo Acevedo Lozano (coords.), Entrevistas ¿para qué? Múltiples escuchas desde diversos cuadrantes. México: Instituto de Investigaciones Dr José María Luis Mora, 2017, pp. 91-125.

Hernández, Isabel, "Programa mínimo de los estudiantes colombianos. Movimiento estudiantil universitario de 1971 por la universidad. Todo un país". Revista Historia de la Educación Colombiana, 2007, pp. 29-57.

Padilla Castilla, Amalfi, "Organizaciones estudiantiles en la Universidad de Cartagena: reconocimiento partidismo y relaciones de poder (1948-1980)". 
Revista Historia de la Educación colombiana, 12, (2009): 123-154. www.udenar.edu.co. 25/02/2011

"Programa mínimo de estudiantes colombianos", http://es.scribd.com/doc/52353497/Programa-Minimo-de-los-EstudiantesColombianos 25/10/2012

"Proyecto de plataforma de la organización estudiantil. presentado por el comité preparatorio del congreso nacional estudiantil", octubre 16 de 1970. http://es.scribd.com/doc/52353499/Proyecto-de-Plataforma-de-la-OrganizacionNacional-Estudiantil 25/10/2012

"Reportaje con Marcelo Torres, Principal dirigente del Movimiento Estudiantil de Colombia en 1971". http://www.juventudpatriotica.com 25/nov./2012 25/10/2012.

\section{Anexo 1}

"Pliego petitorio:

1. Abolición de los Consejos

Superiores universitarios.

a. Creación de organismos de gobierno provisionales, así:

. El rector como presidente del mismo, que participa sin voto;

. Un representante del ministerio de educación que participa con voto;

- Tres estudiantes, elegidos por sus respectivas organizaciones gremiales, que participan con voto;

. Tres profesores, elegidos por sus respectivas organizaciones, que participan con voto.

b. Conformación de una comisión para que estudie el proyecto de reforma de la

Ley Orgánica de las universidades. La comisión estará integrada así:

- Tres representantes de los estudiantes, escogidos por la comisión nacional que ratifique o modifique este encuentro;
3. Conformación inmediata con la misma composición de la que estudiará la reforma a la Ley orgánico, y que estudie los siguientes problemas:

a. Carácter rector de la Universidad Nacional en la educación superior en Colombia.

b. Liquidación de los planes y funciones del ICFES.

c. Financiación estatal de la educación superior teniendo en cuenta los siguientes recursos:

-Cálculo del presupuesto educativo en base al presupuesto ordinario más el de los institutos descentralizados y las empresas estatales;

-Incremento de la participación del Estado en los beneficios resultantes de la explotación de los recursos naturales por el capital extranjero.

d. Investigación científica financiada enteramente por la Nación y planificada por investigadores nacionales.

e. Revisión de todos los contratos y documentos celebrados con entidades extranjeras, por parte de todas las 


. Tres representantes de los profesores
elegidos en los claustros de profesores
de la Universidad Nacional;
. Un representante del Ministerio de
Educación.
c) Establecimiento de un sistema
democrático para la elección de
autoridades universitarias en los
establecimientos públicos y privados
de la educación superior. Este sistema
debe contemplar la participación de
profesores y estudiantes en la
conformación de organismo directivo.
d) Reglamentación nacional y
democrática de la estructura de poder
en las universidades privadas y
públicas.

2. Sobre el presupuesto para la educación

a. Cumplimiento de la asignación del 15 por ciento como mínimo del total del presupuesto de educación para la Universidad Nacional y llenar los déficits actuales de todas las universidades del país.

b. Establecimiento de un control oficial del fisco para las universidades privadas.

c. Congelación de matrículas de todos los establecimientos públicos y privados de educación media y superior a partir de 1970.

d. Suspensión de las cláusulas lesivas a la nación colombiana contenidas en los contratos de las distintas universidades con agencias internacionales de préstamo y que han sido denunciadas por estudiantes y profesores en diferentes universidades del país. universidades y facultades en particular y publicación de los mismos.

f. Las conclusiones de esta comisión sólo tendrán carácter obligatorio para el gobierno después de que tanto las conclusiones como los estudios previos, sean ampliamente analizados, publicados y debatidos por la comunidad universitaria y, finalmente, aprobados en el Encuentro Nacional Universitario.

4. Retiro definitivo de Ocampo Londoño de la Universidad del Valle y ruptura definitiva con la FES (Fundación para la Educación Superior).

5. Legalización del derecho en todos los establecimientos de educación media y superior, tanto privados como públicos

6. Reapertura de la facultad de Sociología de la Universidad Javeriana

El pliego petitorio o programa mínimo estudiantes colombianos establecidos para 1971, se convirtió en el documento que reunía las principales reclamaciones de las diferentes instituciones agremiadas en este órgano representativo"

Este pliego fue establecido durante la asamblea de 25 del mes de abril luego de la III reunión de instituciones de educación superior realizada en Palmira Valle del Cauca. 